\title{
Technological Potential of Antimicrobial Peptides: A Systematic Review
}

\author{
VILMAR MACHADO, JANE GELINSKI ${ }^{1 *}$, C. M. BARATTO ${ }^{1}$, E. M. BORGES ${ }^{2}$, VÂNIAA. VICENTE ${ }^{3}$, MARIANA M. F. \\ NASCIMENTO ${ }^{3}$ AND G. G. FONSECA ${ }^{1,4}$ \\ Federal Institute of Education, Science and Technology Sul-Rio-Grandense, RS, ${ }^{1}$ University of the West of Santa Catarina, SC, \\ ${ }^{2}$ Regional University of Blumenau, SC, ${ }^{3}$ Federal University of Parana, PR, ${ }^{4}$ Federal University of Grande Dourados, MS, Brazil
}

\section{Machado et al.: Review of Antimicrobial Peptides}

\begin{abstract}
Resistance to antibiotics has being considered one of the greatest public health problems worldwide. The objective of this systematic review was to compile important bibliographical references that support the studies related to the biotechnological potential of antimicrobial peptides. Antimicrobial peptides are considered the major components of the innate immune system and work in defence against infections caused by different microorganisms. Many researchers argue that the studies associated with the discoveries of antimicrobial peptides that are more effective in the treatment of infections caused by microorganisms be also directed to the substances produced by insects. The major aspects associated to the technological potential of antimicrobial peptides are, general characteristics, classification, mode of action and prospects for applying, mainly in the pharmaceutical industry. It can be concluded that research for new substances with action against pathogenic microorganisms aim mainly to seek alternatives to the use of antibiotics. In addition, anticancer peptides are small cationic molecules with promising pharmacological use. However, the products for application in the protection of food, treatment of skin infections and its use in the cosmetics industry are those with the greatest potential.
\end{abstract}

Key words: Antibiotics, AMPs, immune system, insect, pharmaceutical industry

The discovery of antibiotics is considered one of the great advances in medicine; its application allows controlling more efficiently infections caused by microorganisms, facilitating the achievement of complex surgical procedures. The use of these substances contributes to the control of infectious diseases by significantly reducing the mortality of humans and animals. The efficiency in the treatment placed the antibiotics among the drugs most prescribed in the world; its indiscriminate use has generated a strong selective pressure favoring the evolution of the bacterial resistance ${ }^{[1-4]}$.

The evolution of resistance of pathogens to antibiotics puts at risk the lives of many patients by reducing the success of modern medicine. The first strains resistant to penicillin was first identified in $1947^{[5]}$ and since then, the number of resistant microorganisms has increased considerably ${ }^{[2-4,6]}$. Davies and Davies ${ }^{[7]}$ stated that many of us have lived in a period that can be referred to as "post-antibiotic age" since some species of pathogens are resistant to more than $50 \%$ of the antibiotic agents used to fight them ${ }^{[8]}$. In 2004, about $70 \%$ of the

*Address for correspondence E-mail: jgelinski@yahoo.com.br

September-October 2019 pathogenic bacteria showed resistance against at least one antibiotic ${ }^{[9]}$. Currently one of the major concerns is the emergence of the so-called super bacteria, which show resistance against multiple antibiotics; in The United States these bacteria cause the death of $99 \%$ of infected people ${ }^{[10,11]}$.

Resistance to antibiotics has determined an increase in mortality rates and costs of treatments, being considered one of the greatest public health problems worldwide ${ }^{[3,12-14]}$. According to the Centers for Disease Control and Prevention ${ }^{[15]}$ this phenomenon causes around 23000 deaths each year in the United States. An additional complication is the reduction of investments in the pharmaceutical industry in developing new antibiotics observed in recent decades ${ }^{[1,16]}$. During this

This is an open access article distributed under the terms of the Creative Commons Attribution-NonCommercial-ShareAlike 3.0 License, which allows others to remix, tweak, and build upon the work non-commercially, as long as the author is credited and the new creations are licensed under the identical terms

Accepted 10 July 2019

Revised 15 March 2019

Received 31 October 2018

Indian J Pharm Sci 2019;81(5):807-814 
period, the search for new substances with action against pathogenic microorganisms has become a constant between researchers in the pharmaceutical area. Among the substances studied are the antimicrobial peptides (AMPs), also known as peptides of host defense.

The AMPs are known since the beginning of the last century, but their potential for application in the pharmaceutical industry, as a replacement for antibiotics, began to be investigated more consistently with the characterization of cecropin by Hultmark et al..$^{[17]}$. This substance with antimicrobial action was isolated from pupae of Hyalophora cecropia (Linnaeus 1758, Fam: Saturniidae) and after this, many other peptides with this characteristic were discovered ${ }^{[18,19]}$.

The objective of this systematic review was to compile important bibliographical references that support the studies related to the biotechnological potential of AMPs. The main topics covered here are: description of the general characteristics of the AMPs, classification, mode of action and technological potential of use. The authors have prioritized literature review articles from the last $10 \mathrm{y}$, but some older ones were considered because they included specific and relevant aspects about peptides.

\section{General characteristics of the AMPs:}

The AMPs are substances evolutionarily ancient found in bacteria, fungi, plants and animals. These substances differ in molecular size, spectrum of action; they are considered the major components of the innate immune system and work in defense against infections caused by viruses, bacteria and fungi ${ }^{[20-33]}$. Furthermore, recent studies indicate that the AMP may exercise activities such as immunological modulators ${ }^{[34,35]}$ in the treatment of cancer ${ }^{[36]}$, in the recovery of skin lesions and as an alternative in the treatment of biofilms formed by pathogenic microorganisms ${ }^{[37]}$. The AMPs, in general, are substances that have fewer than 100 amino acids with a molecular weight below 5000 Daltons, although there have already been found peptides containing between 130 and 150 amino acids. In general, the number of amino acids is less than 60 , ranging between 12 and 50 AA. They are amphipathic molecules (with hydrophobic and hydrophilic regions), with a positive charge (varying between +2 and +9 ) due to the presence of multiple basic amino acids such as lysine, arginine and histidine ${ }^{[38-40]}$.

In vertebrates the synthesis of some AMPs occur in a constitutive way and the production of others can be induced during inflammatory processes; in the aquatic invertebrates these peptides are synthesized rapidly in response to infections caused by microorganisms ${ }^{[38,39]}$. In vertebrates they are produced by several types of cells, such as phagocytes, lymphocytes, epithelial cells of the gastrointestinal tract and urogenital system ${ }^{[40]}$. In insects such substances are produced mainly in grease and promptly released to the hemolymph. Each species, in general, produces a single repertoire of these peptides. The number of AMPs can vary a lot between different species, in insects: for example, more than 50 types of AMPs were identified in Harmonia axiids ${ }^{[41]}$ and only 6 in Apis melifera ${ }^{[42]}$.

Studies on the evolution of genes that encode AMPs indicate the occurrence of cases of duplication followed by evolutionary divergence. This analysis indicated the presence of positive selection favoring changes in load of amino acids, promoting diversification. It was also identified the occurrence of negative selection in areas important for the functional activities of these substances ${ }^{[40,43]}$. The genes that encode antimicrobial proteins are rapidly evolving, which indicated their involvement in the arms race against microorganisms ${ }^{[21,40]}$.

\section{Classes and families:}

The classification of AMPs can be based on several different criteria, i.e., despite of their importance there is a definitive method for their categorization. The database for AMPs (AMP database ${ }^{[44]}$ presents seven different ways for the classification of these substances, the mechanism of synthesis, the origin, the biological function, the properties of the peptides, in threedimensional structure, in the standards of covalent bounds and molecular target. The classification used more frequently is based on structural characteristics, number of amino acids and size, which defines four classes or major groups that could represent several families (fig. 1).

The description below is based on the works of various authors ${ }^{[45-49]}$. Class I $(\alpha$-helix $)$-linear peptides that assume the setting called $\alpha$-helix, examples include cecropin, magainin, pexiganan, dermaseptin and dipteran. Class II ( $\beta$-sheet)-peptides that have two or more $\beta$ chains that are stabilized by the presence of disulfide bonds, such as defensin, protegrin and heliomicin. Class III (extended)-linear peptides that have high amounts of amino acids like proline, histidine, arginine or glycine, examples include drosocin, lebocin and moricin, pyrrhocoricin, indolicidine 
and histatins. Class IV ( $\beta$-hairpin or loops)-peptides that have structures similar to staples connected by bridges of disulfides and possess high quantities of residues of proline, examples, tachyplesins, bactenecin and dodecapeptide. The classes I and II ( $\alpha$-helix and $\beta$-sheet) are the AMPs more common and more studied; as an example of important families are the cecropin and defensin ${ }^{[48,49]}$, respectively (fig. 2).

Cecropin was characterized by Hultmark et al..$^{[17]}$ and, after that, it was identified in different organisms. The study of this peptide has enabled the division of family in five subfamilies or subtypes in consequence of the difference in the composition of amino acids. The precursors of cecropin family cecropin have between 58 and 64 amino acids; the mature peptides are released by cleavage of the signal peptide and have between 35 and 39 amino acids. The mature peptides have no residues of cysteine and form two $\alpha$ helices (an amphiphilic N-terminal and a C-terminal hydrophobic). The family offers a broad spectrum of activity against bacteria (Gram-positive or negative) and fungi ${ }^{[18,21,50]}$.

The members of the family defensin were described in several species and their main feature is the presence of 6 to 8 residues of cysteine, which are involved in the formation of bridges of molybdenum disulfide that maintain the structure of the peptide ( $\beta$-sheet). They are alkaline peptides rich in arginine containing between 16 and 50 amino acids; these are synthesized as a prepeptide that would go through several modifications before being released in the active form. The members of this family differ in size, being known, currently, the subfamilies $\alpha, \beta$ and $\theta$ defensin. In addition, the family defensin have members with action against bacteria, fungi and protozoa ${ }^{[18,21,51]}$.

The diversity and variation in the composition of amino acids observed between the AMP is one of the difficulties for the definition of procedures for classification and identification of these substances, especially the definition of families. As a result, in recent years several works based in bioinformatics have been developed, aiming to establish methodologies and most appropriate criteria for the classification of $\mathrm{AMPS}^{[43,50-53]}$.

\section{Mode of action and technological potential:}

The action of AMPs may involve changes in the plasma membrane and intracellular elements, as in DNA, in the processes of synthesis and folding of proteins. The first step of the action of AMPs involves their interaction with the plasma membrane. This interaction depends on the specific characteristics of the membranes of cells and peptides ${ }^{[54]}$.

The AMPs are attracted by electrostatic forces to the negative portions of the phospholipids of the cell membrane which are connected to the lipopolysaccharides in Gram-negative bacteria, to teichoic acid, lipoteichoic and lysylphosphatidylglycerol in Gram-positive bacteria. After that, the AMPs directly interact with the phospholipids of the plasma membrane. The interaction between the AMPs and the double layer of phospholipids stems from the amphiphile nature of both. In this process the positive charges of AMP are important for their link to regions with negative charges of the membrane, while the hydrophobic portion is important for insertion in the double layer ${ }^{[49,55]}$.

The difference in the chemical composition of the plasma membrane of prokaryotes and eukaryotes explains the selectivity of the AMPs for bacteria. Furthermore, the bacterial cells have no cholesterol ${ }^{[56]}$. The action of the AMPs against tumors is based on differences in the chemical composition of the plasma membrane of the malignant cells ${ }^{[57]}$. The mechanism of action of AMP does not involve specific receptors, which reduces the speed of evolution of resistance on the part of the pathogens ${ }^{[58]}$. The recent models known to explain the effects of the AMPs on the plasma membrane are, Barrel-stave model, Toroidal pore model and carpet model. These models differ in how

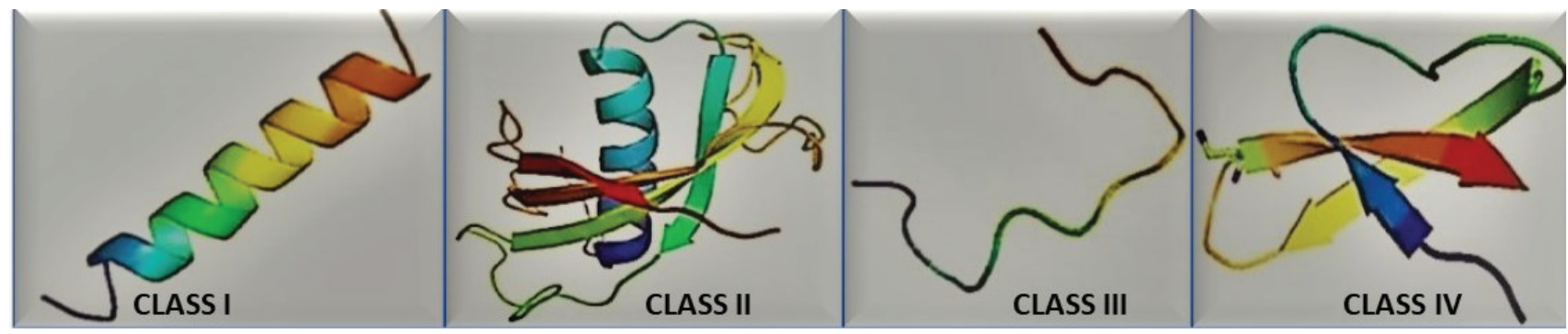

Fig. 1: Classes of antimicrobial peptides Class I- $\alpha$-helix, class II- $\beta$-sheet, class III- extended helix and class IV- $\beta$-hairpin or loops. Modified from Peters et al. ${ }^{[45]}$ 
they explain the interaction and/or deterioration caused

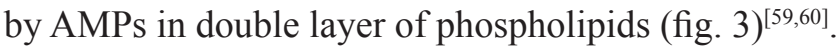

The models Barrel-stave and Toroidal involve the insertion of aggregates of AMPs in dual layer and the formation of pores, which can lead to changes in the flow of calcium, membrane depolarization, loss of energy and, in some cases, induce apoptosis. At the model of tappet (carpet) there is the passage of the AMP by double layer of lipids leading to dissolution or destruction of the plasma ${ }^{[54,61]}$.

In the Barrel stave model the process is directed from the hydrophilic interactions of the peptides

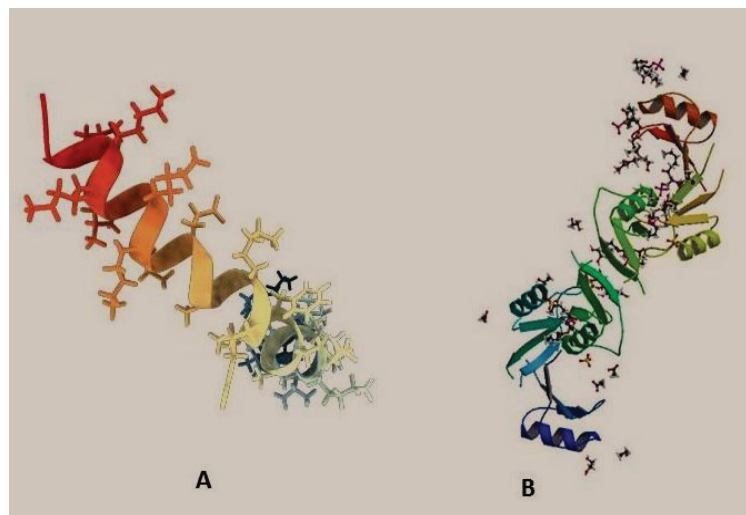

Fig. 2: 3D structures of class I and II AMPs

A: Cecropin-like peptide; B: defensin NSD7. Images from RCSB Protein Data Bank (PDB) A. PDB ID $2 M^{M M^{[48]}}$ and B. PDB ID 5KK4 ${ }^{[49]}$ with the external membrane of the bilayer. From a peptide complex with perpendicular orientation to the membrane, it is inserted through the hydrophobic region of the bilayer forming a channel (fig. 3) ${ }^{[8,60]}$. Already the Toroidal model (fig. 3) occurs by the transition of the peptide from an inactive state to an active. The peptides are reoriented perpendicularly into the hydrophobic region of the bilayer (active state) and are associated with lipid molecules in a transitional multipore state, known as supramolecular-lipid dynamic complex. The rupture of the membrane becomes irreversible besides increased transmembrane movement of lipids (fig. 3, red arrow $)^{[60]}$.

In the carpet model the positive charges of helical cationic peptides plus negatively charged phospholipid heads interact and are oriented towards the outside of the membrane. Upon reaching a critical concentration, the peptides undergo rotation and the phospholipids present are redirected. Consequently, there is layer collapse and formation of micelles with hydrophobic core and pore formation in the membrane (fig. 3) ${ }^{[8,60]}$.

Recent studies showed the existence of complementary mechanisms which act on the intra cell components. After the interaction with the membrane the AMP bind to intracellular molecules by inhibiting the synthesis of DNA, RNA, proteins and/or components of the plasma membrane $\mathrm{e}^{[36,62]}$.
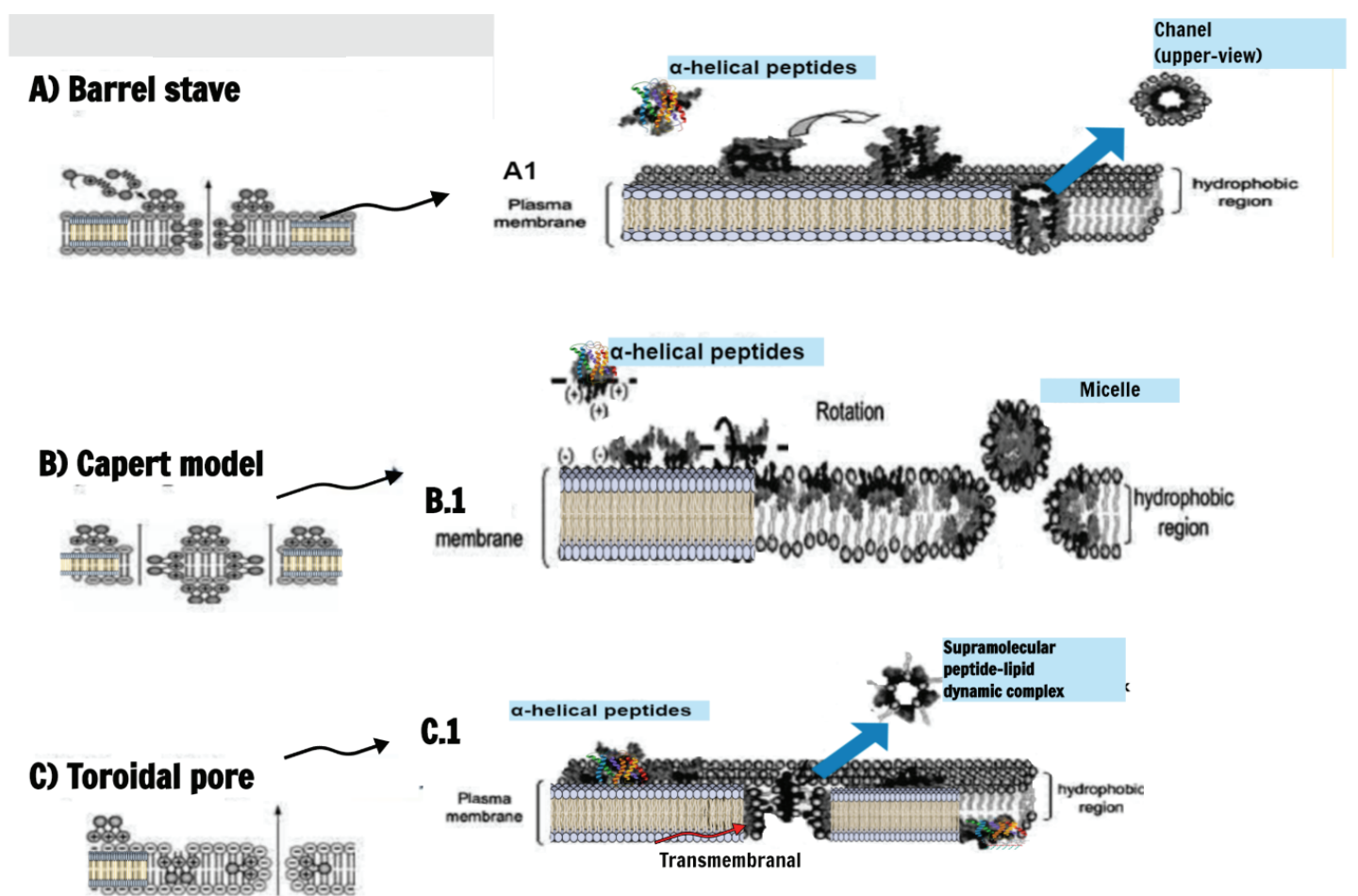

Fig. 3: Models that explain interaction of AMPs with double layer of phospholipids

Schemes of the 3 models that explain the interaction of AMPs with double layer of phospholipids. A, B and C adapted by permission from Macmillan Publishers Ltd, Nature Reviews Nephology ${ }^{[59]} \mathrm{A} 1, \mathrm{~B} 1$ and $\mathrm{C} 1$ are modified from López-Meza et al..$^{[60}$ 


\section{Perspectives:}

The efficiency of the AMPs has been demonstrated by several studies over time, but nevertheless there are few products available on the market. Among the products marketed are: polymyxin B, colistin, tyrocidin, gramicidin, bactracin and daptomycin, lucinactant, peginesatide, pasireotide, carfilzomib, linaclotide, teduglutide ${ }^{[62]}$. In recent years, approximately 140 AMPs are in different stages of analysis to the authorization for commercial production ${ }^{[63]}$. In addition, there are several studies analyzing the efficiency of some AMPs in fighting infections caused by fungi and bacteria in transgenic plants that express the codifying gene of the peptide $^{[38,64]}$.

The studies carried out demonstrated the great potential of AMPs for the pharmaceutical industry, either by their form of action that hinders the development of resistance or by the diversity of types available for tests and assessments. The evolution of resistance to the AMPs would depend on a reconfiguration in the structure of the membrane - a process much more complex and harder to happen ${ }^{[56,65]}$. On the other hand, the AMPs are produced by all living beings, i.e., are a source almost limitless for research and evaluations ${ }^{[25,32,33,66]}$. In addition, it is necessary to remember their efficiency and broad spectrum of action.

Due to that, a question is evident: what are the major difficulties for the exploitation of this potential by the pharmaceutical industry? Among the main difficulties to use the AMPs as a method of control of microorganisms are the possibility to be toxic to mammalian cells; its proteolytic degradation and the costs for its development for pharmaceutical applications ${ }^{[8,67]}$. The development of AMP with up to 30 amino acids has a cost within the limit that large companies are willing to invest in the development of new products. The costs for development of larger peptides are considerably high ${ }^{[45,68]}$. These obstacles are related to up-scaling and licensing of peptides, but despite this, it is estimated that more than 500 derived peptides are under development ${ }^{[68,69]}$.

The AMPs are rapidly degraded by the action of proteases inside the human body; this reduces their availability and makes it difficult to maintain the dose of the medicine at effective concentrations ${ }^{[70]}$. The problems of stability of the AMP in physiological conditions can be overcome through specific changes in their chemical composition and/or structure, such as the replacement and/or addition of amino acids or other chemical groups. These chemical changes may also contribute to increase the efficiency of $\mathrm{AMPs}^{[71]}$. These changes can be performed using traditional methodologies for the drug's production.

Among the strategies used to minimize the effects of the AMP in the organism treated and increase its half-life stand out: its association with substances which increase the solubility, association with substances, which increase their aggregation capacity and construction of proteins with a capacity of self-cleavage ${ }^{[71,72]}$. In recent years, several studies have examined the use of nanotechnology to solve stability problems, application, absorption and movement of peptides inside of the body, facilitating its pharmacological use ${ }^{[73,74]}$.

In addition to the applications in the treatment of infections by microorganism's products based on AMP may be important in the food industry and cosmetics. The food industry can use the AMP as a substitute of synthetic preservatives for food safer production preventing the growth and development of pathogenic microorganisms and/or avoiding contamination ${ }^{[65,75]}$.

On the other hand, many AMP are active against dermatological pathogens important and relevant to the cosmetics industry. They can be used, therefore, in the making of products for prophylactic application and personal care contributing to maintaining the health of the $\operatorname{skin}^{[75,76]}$.

AMPs are, for sure, a great option in the fight of pathogenic microorganisms to humans, animals and plants. A relevant point is the fact that they are substances produced by all living organisms, which puts at the disposal of the researchers an inexhaustible source of studies. The major problems associated with the application of these substances can be overcome by using technologies already applied by the pharmaceutical industry, especially for molecules with fewer than 30 amino acids. The products for application in the protection of food, treatment of skin infections and its use in the cosmetics industry are now those with the greatest potential. Certainly, in the near future, problems for its use in oral and/or intravenous administration will be overcome.

In addition, there are AMPs with selective antitumor mechanisms (cationic peptides) with amphipathic structure that are able to cause cell membrane disruption $^{[54,57]}$. These anticancer peptides have great in vivo potential but their activity against cancer cells is lower than antimicrobial activity. 
Many researchers argue that the studies associated with the discoveries of AMPs more effective in the treatment of infections caused by microorganisms be also directed to the substances produced by insects. The reasons for this suggestion are the evolutive success that allows insects to occupy a variety of habitats; an important part of this success can be attributed to the efficiency of their immune system. In addition, there are more than 30 million species of insects, i.e., a huge source of resources to prospect for new substances with application in medicine, food industry and cosmetics as substitutes or/and for use in conjunction with the antibiotics $^{[38,40,44,45,77]}$.

From evolutionary perspective, even if the researchers find AMP very efficient in control of microorganisms, it must be borne in mind that this success may be temporary, because evolution is an ongoing process ${ }^{[78]}$. Therefore, it is highly likely that at some time in the future, some strains of bacteria develop resistance or decreased sensitivity to AMP used in the treatment of infections. This is a facet of the mankind's arms race against pathogenic microorganisms that should not be forgotten. So, part of the resources should be invested continually in the development of new strategies and products for treatment and control of pathogenic agents. An evidence of this need for continuous investment comes from several studies about the possibility of resistance of bacteria to $\mathrm{AMPS}^{[68,79-82]}$.

\section{Acknowledgments:}

The authors are grateful to the Capes/PNPD-Postdoctoral Fellowship Program, Brazil.

\section{Financial support/funding:}

This study was financed in part by the Coordenação de Aperfeiçoamento de Pessoal de Nivel Superior Brazil (CAPES)-Finance code 001.

\section{Conflict of interest:}

The authors declare that they have no conflict of interest. We affirm that funding sponsors had no role in the design of the study; in the collection analyses, or data interpretation in the writing of this manuscript, and the decision to publish this review.

\section{REFERENCES}

1. Ferri M, Ranucci E, Romagnoli P, Giaccone V. Antimicrobial Resistance: A Global Emerging Threat to Public Health Systems. Crit Rev Food Sci Nutr 2015;57(13):2857-76.

2. Roca I, Akova M, Baquero F, Carlet J, Cavaleri M, Coenen S, et al. The global threat of antimicrobial resistance: science for intervention. New Microbes New Infect 2015;6:22-9.

3. Smith RA, M'ikanatha NM, Read AF. Antibiotic resistance: a primer and call to action. Health Commun 2015;30:309-14.

4. Watkins RR, Bonomo RA.2016. Overview: Global and Local Impact of Antibiotic Resistance. Infect Dis Clin North Am 2016; 30:313-22.

5. Miller CP. Development of bacterial resistance to antibiotics. J Am Med Assoc 1947;135:749-51.

6. Hughes D, Andersson DI. Evolutionary consequences of drug resistance: shared principles across diverse targets and organisms. Nat Rev Genet 2015;16:459-71.

7. Davies J, Davies D. Origins and evolution of antibiotic resistance. Microbiol Mol Biol Rev 2010;74(3):417-33.

8. Di Giulio A, Zhao HN. Antimicrobial peptides: Basic mechanisms of action and emerging pharmacological interest. Asian J Biochem 2006;1:28-40.

9. Katz ML, Mueller LV, Polyakov M, Weinstock SF. Where have all the antibiotic patents gone? Nat Biotechnol 2006;24:1529-31.

10. Bie B, Tang L, Treise DM. Be aware of superbugs: Newspaper coverage of NDM-1 in India, UK, and the USA. Asian J Commun 2016;26:58-75.

11. Kumar H. Multiple Antibiotic Resistance Patterns of the Enterobacteriaceae in the Untreated Municipal Sewage. J Clin Diagn Res 2016;10(9):DL01-DL02.

12. Garrett JH. An Era of Antimicrobial Resistance: Imminent Threats of Superbugs to Vascular Access Clinicians and Patients. J Assoc Vasc Access 2015;20:133-6.

13. Penesyan A, Gillings M, Paulsen IT. Antibiotic discovery: combatting bacterial resistance in cells and in biofilm communities. Molecules 2015;20(4):5286-98.

14. Patrick K. Antibiotic stewardship and pharma's social conscience. CMAJ 2016;188:483-3.

15. Centers for Disease Control and Prevention (US). Antibiotic resistance threats in the United States. Centres for Disease Control and Prevention, US Department of Health and Human Services; 2013. Available from: https://www.cdc.gov/ drugresistance/biggestthreats/tracking.html.

16. Projan SJ, Shlaes DM. Antibacterial drug discovery: is it all downhill from here? Clin Microbiol Infect 2014;10:18-22.

17. Hultmark D, Engström A, Bennich H, Kapur R, Boman HG. Insect immunity: isolation and structure of cecropin D and four minor antibacterial components from Cecropia pupae. Eur J Biochem 1982;127(1):207-17.

18. Yi HY, Chowdhury M, Huang YD, Yu XQ. Insect antimicrobial peptides and their applications. Appl Microbiol Biotechnol 2014;98:5807-22.

19. Rahnamaeian M, Cytryńska M, Zdybicka-Barabas A, Dobslaff $\mathrm{K}$, Wiesner J, Twyman RM, et al. Insect antimicrobial peptides show potentiating functional interactions against Gramnegative bacteria. Proc Biol Sci 2015;282:20150293.

20. Phoenix DA, Dennison SR, Harris F. Antimicrobial Peptides: Their History, Evolution, and Functional Promiscuity. In: Phoenix DA, Dennison SR, Harris F, editors. Antimicrobial Peptides. Weinheim, Germany: Wiley-VCH Verlag GmbH \& Co.; 2013.

21. Tassanakajon A, Somboonwiwat K, Amparyup P. Sequence diversity and evolution of antimicrobial peptides in invertebrates. Dev Comp Immunol 2015;48(2):324-41.

22. Lecaille F, Lalmanach G, Andrault PM. Antimicrobial proteins and peptides in human lung diseases: a friend and foe partnership with host proteases. Biochimie 2016;122:151-68. 
23. Salas CE, Badillo-Corona JA, Ramírez-Sotelo G, OliverSalvador C. Biologically active and antimicrobial peptides from plants. BioMed Res Int 2015;2015:102129.

24. Guzmán-Rodríguez JJ, Ochoa-Zarzosa A, López-Gómez R, López-Meza JE. Plant Antimicrobial Peptides as Potential Anticancer Agents. Biomed Res Int 2015;2015:735087.

25. Makarova O, Rodriguez-Rojas A, Eravci M, Weise C, Dobson A, Johnston $\mathrm{P}$, et al. Antimicrobial defense and persistent infection in insects revisited. Philos Trans R Soc Lond B Biol Sci 2016;371:20150296.

26. Chernysh S, Gordya N, Suborova T. Insect Antimicrobial Peptide Complexes Prevent Resistance Development in Bacteria. PLoS One 2015;10:e130788.

27. Dong Z, Song Q, Zhang Y, Chen S, Zhang X, Zhao P, et al. Structure, evolution, and expression of antimicrobial silk proteins, seroins in Lepidoptera. Insect Biochem Mol Biol 2016;75:24-31.

28. Faruck MO, Yusof F, Chowdhury S. An overview of antifungal peptides derived from insect Peptides. Peptides 2015;80:80-8.

29. Calhoun DM, Woodhams D, Howard C, LaFonte BE, Gregory JR, Johnson PT. Role of Antimicrobial Peptides in Amphibian Defense Against Trematode Infection. Ecohealth 2016;13(2):383-91.

30. Lacerda AF, Pelegrini PB, de Oliveira DM, Vasconcelos ÉA, Grossi-de-Sá MF. Anti-parasitic Peptides from Arthropods and their Application in Drug Therapy. Front Microbiol 2016;7:91.

31. Badapanda C, Chikara SK. Lepidopteran Antimicrobial Peptides (AMPs): Overview, Regulation, Modes of Action, and Therapeutic Potentials of Insect-Derived AMPs. In: Raman C, Goldsmith MR, Agunbiade TA, editors. Short Views on Insect Genomics and Proteomics, Vol 2. Switzerland: Springer; 2016. p. 141.

32. Destoumieux-Garzón D, Rosa RD, Schmitt P, Barreto C, Vidal-Dupiol J, Mitta G, et al. Antimicrobial peptides in marine invertebrate health and disease. Philos Trans R Soc Lond B Biol Sci 2016;371:20150300.

33. Martínez B, Rodríguez A, Suárez E. Antimicrobial Peptides Produced by Bacteria: The Bacteriocins. In: Villa TG, Vinas M, editors. New Weapons to Control Bacterial Growth. Switzerland: Springer; 2016. p. 15-38.

34. Mansour SC, Pena OM, Hancock RE. Host defense peptides: front-line immunomodulators. Trends Immunol 2014;35(9):443-50.

35. Henkel A, Tausch L, Pillong M, Jauch J, Karas M, Schneider $\mathrm{G}$, et al. Boswellic acids target the human immune systemmodulating antimicrobial peptide LL-37. Pharmacol Res 2015; 102:53-60.

36. Theansungnoen $\mathrm{T}$, Maijaroen S, Jangpromma N, Yaraksa N, Daduang S, Temsiripong T, et al. Cationic Antimicrobial Peptides Derived from Crocodylus siamensis Leukocyte Extract, Revealing Anticancer Activity and Apoptotic Induction on Human Cervical Cancer. Protein J 2016;35(3):110.

37. Pletzer D, Hancock RE. Anti-biofilm peptides: Potential as broad-spectrum agents. J Bacteriol 2016;198:2572-8.

38. Ganz T. Defensins: antimicrobial peptides of innate immunity. Nat Rev Immunol 2003;3(9):710-20.

39. Bahar AA, Ren D. Antimicrobial peptides. Pharmaceuticals 2013;6:1543-75.

40. Mylonakis E, Podsiadlowski L, Muhammed M, Vilcinskas A. Diversity, evolution and medical applications of insect antimicrobial peptides. Philos Trans R Soc Lond B Biol Sci 2016;371:20150290.

41. Vilcinskas A, Mukherjee K, Vogel H. Expansion of the antimicrobial peptide repertoire in the invasive ladybird Harmonia axyridis. Proc Biol Sci 2013;280:20122113.

42. Evans JD, Aronstein K, Chen YP, Hetru C, Imler J-L, Jiang $\mathrm{H}$, et al. Immune pathways and defence mechanisms in honey bees Apis mellifera. Insect Mol Biol 2006;15:645-56.

43. Duda TF, Vanhoye D, Nicolas P. Roles of diversifying selection and coordinated evolution in the evolution of amphibian antimicrobial peptides. Mol Biol Evol 2012;19(6):858-64.

44. Wang Z, Wang G. APD: the Antimicrobial Peptide Database. Nucleic Acids Res 2004;32:D590-2.

45. Peters BM, Shirtliff ME, Jabra-Rizk MA. Antimicrobial peptides: primeval molecules or future drugs? PLoS Pathog 2010;6:e1001067.

46. Ahmad A, Ahmad E, Rabbani G, Haque S, Arshad M, Khan RH. Identification and design of antimicrobial peptides for therapeutic applications. Curr Protein Pept Sci 2012;13:21123.

47. Harrison PL, Abdel-Rahman MA, Strong PN, Tawfik MM, Miller K. Characterisation of three alpha-helical antimicrobial peptides from the venom of Scorpio maurus palmatus. Toxicon 2016;117:30-36.

48. Godreuil S, Leban N, Padilla A, Hamel R, Luplertlop N, Chauffour A, et al. Aedesin: structure and antimicrobial activity against multidrug resistant bacterial strains. PLoS One 2014;9:e105441-e105441.

49. Kvansakul M, Lay FT, Adda CG Veneer PK, Baxter AA, Phan TK, et al. Crystal Structure of the Plant Defensin NsD7 bound to Phosphatidic Acid. Proc Natl Acad Sci 2016;113:11202-7.

50. Hu H, Wang C, Guo X, Li W, Wang Y, He Q. Broad activity against porcine bacterial pathogens displayed by two insect antimicrobial peptides moricin and cecropin B. Mol Cells 2013;35:106-14.

51. Rodríguez-García MJ, García-Reina A, Machado V, Galián J. Identification, structural characterisation and expression analysis of a defensin gene from the tiger beetle Calomera littoralis (Coleoptera: Cicindelidae). Gene 2016;589:56-62.

52. Gogoladze G, Grigolava M, Vishnepolsky B, Chubinidze M, Duroux P, Lefranc MP, et al. DBAASP: database of antimicrobial activity and structure of peptides. FEMS Microbiol Lett 2014;357:63-8.

53. Waghu FH, Barai RS, Gurung $\mathrm{P}$, Idicula-Thomas $\mathrm{S}$. CAMPR3: a database on sequences, structures and signatures of antimicrobial peptides. Nucleic Acids Res 2016;44(D1):D1094-7.

54. Nguyen LT, Haney EF, Vogel HJ. The expanding scope of antimicrobial peptide structures and their modes of action. Trends Biotechnol 2015;29(9):464-472.

55. Malanovic N, Lohner K. Gram-positive bacterial cell envelopes: The impact on the activity of antimicrobial peptides. Biochim Biophys Acta 2015;1858:936-9465.

56. Epand RM. Host defense peptides and their potential as therapeutic agents. Switzerland: Springer; 2016.

57. Kuroda K, Okumura K, Isogai H, Isogai E. The human cathelicidin antimicrobial peptide LL-37 and mimics are potential anticancer drugs. Front Oncol 2015;5:144.

58. Rabanal F, Cajal Y. Therapeutic potential of antimicrobial peptides. In: Villa, TG, Vinas M, editors. New weapons to control bacterial growth. Switzerland: Springer; 2016. p. 43351 . 
59. Becknell B, Schwaderer A, Hains, D.S. Spencer D. Amplifying renal immunity: the role of antimicrobial peptides in pyelonephritis. Nat Rev Nephrol 2015;11:642-55.

60. López-Meza JE, Ochoa-Zarzosa A, Aguilar JA, Loeza-Lara PD. Antimicrobial Peptides: Diversity and perspectives for their biomedical application. In: Olsztynska S, editor. Biomedical engineering, trends, research and technologies. London, UK; IntechOpen: 2011. p. 275-304.

61. Henderson LC, Li J, Nation RL, Velkov T, Pfeffer FM. Developing an anion host for lipid A binding and antibacterial activity. Chem Commun 2010;46:3197-9.

62. Gagnon MG, Roy RN, Lomakin IB, Florin T, Mankin AS, Steitz, TA. Structures of proline-rich peptides bound to the ribosome reveal a common mechanism of protein synthesis inhibition. Nucleic Acids Res 2016;44:2439-50.

63. Uhlig T, Kyprianou T, Martinelli FG, Oppici CA, Heiligers D, Hills D. The emergence of peptides in the pharmaceutical business: From exploration to exploitation. EuPA Open Proteomics 2014;4:58-69.

64. Anuradha TS, Divya K, Jami SK, Kirti PB. Transgenic tobacco and peanut plants expressing a mustard defensin show resistance to fungal pathogens. Plant Cell Rep 2018;27:177786.

65. Chou S, Shao C, Wang J, Shan A, Xu L, Dong N, et al. Short, multiple-stranded $\beta$-hairpin peptides have antimicrobial potency with high selectivity and salt resistance. Acta Biomater 106;30:78-93.

66. Meneguetti BT, Machado LD, Oshiro KG, Nogueira ML, Carvalho CME, Franco OL. Antimicrobial peptides from fruits and their potential use as biotechnological tools-a review and outlook. Front Microbiol 2016;7:2136.

67. Dawson RM, Liu CQ. Properties and applications of antimicrobial peptides in biodefense against biological warfare threat agents. Crit Rev Microbiol 2008;34:89-107.

68. Rafferty J, Nagaraj H, McCloskey AP, Huwaitat R, Porter $\mathrm{S}$, Albadr A, et al. Peptide Therapeutics and the Pharmaceutical Industry: barriers encountered translating from the laboratory to patients. Curr Med Chem 2016;23:4231-59.

69. da Costa JP, Cova M, Ferreira R, Vitorino R. Antimicrobial peptides: an alternative for innovative medicines? Appl Microbiol Biotechnol 2015;99(5):2023.
70. Pushpanathan M, Gunasekaran P, Rajendhran J. Antimicrobial peptides: versatile biological properties. Int J Pept 2013;1-15.

71. Heinis C, Winter G. Encoded libraries of chemically modified peptides. Curr Opin Chem Biol 2015;26:89-98.

72. Aguirre TAS, Teijeiro-Osorio D, Rosa M, Coulter IS, Alonso MJ, Brayden D. Current status of selected oral peptide technologies in advanced preclinical development and in clinical Trials. Adv Drug Deliv Rev 2016;15:223-41.

73. Wolf D, Mascher T. The applied side of antimicrobial peptideinducible promoters from Firmicutes bacteria: expression systems and whole-cell biosensors. Appl Microbiol Biotechnol 2016;100(11):4817-29.

74. Antosova Z, Mackova M, Kral V, Macek T. Therapeutic application of peptides and proteins: parenteral forever? Trends Biotechnol 2009;27(11):628-35.

75. Umerska A, Matougui N, Groo AC, Saulnier P. Understanding the adsorption of salmon calcitonin, antimicrobial peptide AP114 and polymyxin B onto lipid nanocapsules. Int J Pharm 2016;506(1-2):191-200.

76. Rakers S, Niklasson L, Steinhagen D, Kruse C, Schauber J, Sundell K, et al. Antimicrobial peptides (AMPs) from fish epidermis: perspectives for investigative dermatology. J Invest Dermatol 2013;133:1140-49.

77. Clausen M-L, Agner T. Antimicrobial Peptides, Infections and the Skin Barrier. Curr Probl Dermatol 2016;49:38-46.

78. Gosset CC, Do Nascimento J, Augé MT, Bierne N. Evidence for adaptation from standing genetic variation on an antimicrobial peptide gene in the mussel Mytilus edulis. Mol Ecol 2014;23(12):3000-12.

79. Andersson LI, Hughes D, Kubicek-Sutherland JZ. Mechanisms and consequences of bacterial resistance to antimicrobial peptides. Drug Resist Updat 2016;26:43-57.

80. Joo HS, Fu CI, Otto M. Bacterial strategies of resistance to antimicrobial peptides. Philos Trans R Soc Lond B Biol Sci 2016;371(1695):20150292.

81. Deslouches B, Di YP. Antimicrobial peptides with selective antitumor mechanisms: prospect for for anticancer applications. Oncotarget 2017:8;46635-51.

82. Rolff J, Schmid-Hempel P. Perspectives on the evolutionary ecology of arthropod antimicrobial peptides. Philos Trans R Soc Lond B Biol Sci 2016;371:20150297. 